\title{
Acolhida Cidadã/Solidária da FURG: uma política de acolhimento aos ingressantes com protagonismo da comunidade universitária
}

\author{
Welcoming FURG Citizen/Solidarity: a welcoming policy for \\ newcomers with a leading role in the university community
}

\author{
Sirlei Nadia Schirmer (sirleischirmer@furg.br) \\ Doutoranda e Pedagoga Escolar da Universidade do Federal do Rio Grande - FURG
}

Daniele Barros Jardim (danielejardim@furg.br)

Doutora em Educação Ambientale Peda go ga Escolar da Universidade Federal do Rio Gra nde FURG

Tatiane Godinho da Costa (tati281170@ hotmail.com)

Mestre em Educação pela Universidade Federal do Rio Grande - FURG

Joice Rejane Pardo Maurell (joicerejane@furg.br)

Doutoranda e Pedagoga Escolar da Universidade Federal do Rio Grande -FURG

Resumo: Este relato tem como objetivo apresentar o Programa de Acolhida Cidadã/Solidária da FURG, enquanto metodologia institucional de acolhimento aos estudantes ingressantes, que substitui o trote universitário, bem como aposta no protagonismo dos envolvidos no desenvolvimento das atividades. O Programa traduz uma nova cultura que propôs ações solidárias e respeitosas à dignidade e à boa convivência nos espaços sociais, dentro e fora do ambiente universitário, substitu in do, nessa última década, o conhecido trote. Partindo da premissa de Caetano Veloso que já dizia "É proibido, proibir", a universidade criou em 2010 a Acolhida Cid adã, f azen do com que o conceito e a cultura do trote universitário fosse se desconstruindo en tre os estudantes. O referencial teórico está baseado nas elucidações de Brandão (2002), Freire (1997, 2000 e 2007), Gadotti (2003), Mattozo (1985) e Vázquez (1999). Como resultados, percebemos que os vínculos estabelecidos pelos veteranos no processo de acolhimento têm um impacto positivo na adaptação dos calouros, o que influencia consequentemente no desempenho acadêmico e, muitas vezes, minimiza os processos de retenção e evasão, que muito tem nos mobilizado no seu enfrenta mento, enquanto instituição. Atinente, as atividades da Acolhida Cidadã têm contribuído para melhorar a qualidade do ensino e da formação ampliada dos estudantes.

Recebido em: 30 /04/ 2020 
Palavras-chave: Acolhida Cidadã; protagonismo; metodologia institucional; trote universitário; FURG.

Abstract: This report aims to present the FURG Citizen / Solidarity Reception Program, as an institutional methodology for welcoming incoming students, which replaces university hoax, as well as betting on the protagonism of those involved in the development of activities. The Program translates a new culture that proposed actions that are solidary and respectful of dignity and good coexistence in social spaces, in side and outside the university environment, replacing, in the last decade, the well-known hoax. Based on the premise of Caetano Veloso, who already said "It is forbidden, forbid", in 2010 the Acolhida Cidadã was created, causing the conce pt and culture of university hazing to be deconstructed among students. The theoretical framework is based on the elucidations of Brandão (2002), Freire (1997, 2000 and 2007), Gadotti (2003), Mattozo (1985) and Vázquez (1999). As a result, we realize that the bonds established by veterans in the welcoming process have a positive impact on the adaptation of freshmen, which consequently influences academic performance and, often, minimizes the retention and evasion processes, which have mobilized us a lot in their coping as an institution. As a result, the activities of Acolhida Cidadã have contributed to improving the quality of education and expanded training for students.

Keywords: Welcome Citizen; leadership; institutional methodology; university trot; FURG

\section{CONSIDERAÇÕES INICIAIS}

A Universidade Federal do Rio Grande - FURG em 2010, aprovou a Deliberação n ${ }^{\circ}$ 164/2010 do Conselho de Ensino, Pesquisa, Extensão e Administração - COEPEA, que institui e orienta a execução do Programa de Acolhida Cidadã/Solidária. De forma corajosa e pioneira, a FURG definiu o que entende por trote violento e preparou -se para não apenas proibir, mas promover e organizar a Acolhida Cidadã, visando à realização de ações solidárias e respeitosas à dignidade e à boa convivência nos e spaços sociais, dentro e fora do ambiente universitário.

Por compreender que a acolhida ao estudante calouro é uma importante etapa do processo de integração à vida universitária e frente às crescentes expressões de violência nos chamados trotes, a Acolhida Cidadã tornou-se, hoje, uma metodologia institucional de trabalho, divida em três etapas/ano - Acolhida Cidadã do $1^{\circ}$ semestre, Acolhida

Recebido em: $30 / 04 / 2020$ 
Cidadã do $2^{\circ}$ semestre e Seminário de Encerramento da Acolhida. O objetivo inicial do Programa foi o combate às ações que geram violência, humilhação e outras atrocidades que eram registradas a cada início de ano letivo, principalmente.

Mas, o que significa para você "acolher" no ambiente universitário? Parece uma questão simples, mas faz toda diferença na permanência e no desenvolvimento dos estudantes na Universidade. Para Ferreira (1975) “acolher" é dar amparo, admitir, aceitar, dar ouvidos, dar crédito, agasalhar, receber, atender, admitir, enfim, em seus múltiplos sentidos, é uma ação de aproximação, um “estar com” e u m "estar perto de". Isto é, uma atitude inclusiva e que desenvolve o pertencimento.

É nessa concepção que a Acolhida Cidadã foi se construindo na Universidade Federal do Rio Grande - FURG, que com seu slogan "Acolhendo pessoas, abraçando culturas e construindo conhecimento", incentiva à comunidade universitária ao protagonismo estudantil há 10 anos. Assim, no Programa, o estar em relação com algo ou alguém é no sentido de "estar perto de", anunciando o acolhimento como um ato que perpassa a ética, a estética e a política de uma universidade humanizada: a ética, no compromisso com o reconhecimento do outro, com o modo de acolhê-lo em suas diferenças, suas maneiras de viver, sentir e "estar no e com o mundo" (FREIRE, 1997); a estética, porque apresentam os movimentos do dia-a-dia do sujeito, as suas estratégias que colaboram para a construção de nossa própria humanidade e do viver (VÁZQUEZ, 1999); e a política, porque se refere ao compromisso coletivo de "estar com", estimulando os protagonismos e vida nos diversos encontros no "Compromis so com o ser mais deste homem" (FREIRE, 2007).

Desta forma, a presente escrita defende que o acolhimento está presente em todas as relações e encontros que fazemos na vida. Logo, temos que reconhecer que a FURG faz à diferença quando estimula estudantes, docentes e Técnicos Administrativos em Educação (TAE) ao protagonismo acadêmico, ao promover ações de acolhimento dos calouros em suas diversas atividades, no início e ao longo do ano letivo. 
Esse texto apresenta a aprovação da Acolhida Cidadã, enquanto programa e metodologia institucional de acolhimento aos estudantes ingressantes, que substitui o trote universitário e aposta no protagonismo dos envolvidos. Na sequência apresenta as responsabilidades de cada segmento sobre a sua execução e a sua ampliação. Por fim, evidencia-se a metodologia utilizada para produzir essa escrita, destacando as categorias que emergiram na análise das atividades descritas na programação da acolhida nos últimos três anos, em especial, e algumas reflexões sobre o impacto do Programa na formação acadêmica.

\section{SOBRE A PROIBIÇÃO DO TROTE NA FURG}

A Resolução 008/2004 (FURG), foi publicada no ano de 2004, proibin do o trote organizado e praticado por estudantes veteranos, envolvendo calouros na FURG. De 2004 a 2009 a FURG experienciou cinco anos sem sucesso dessa suspensão, até a gestão perceber, mediante algumas ações que poucos cursos já realizavam que não bastava apenas proibir, mas fazia-se necessário (res)significar essa tradição com os estudantes, mediante uma nova lógica de acolhimento. Para tanto, foi questionado numa avaliação do Programa da Acolhida Cidadã realizada em 2019, o que pensam os docentes, discentes e TAE sobre a proibição do trote na FURG?

Diante das avaliações do Programa da Acolhida Cidadã, conclui-se que não é fácil mudar hábitos socialmente construídos, mas é preciso paciência e persistência para que esta mudança seja feita e as novas práticas se constituam como cultura de acolhimento. As atividades educativas da Acolhida deverão persistir sempre neste sentido, orientando e propondo novas ações, até que seja totalmente erradicada as práticas negativas do antigo trote. Vislumbra-se uma instituição na acolha naturalmente no abraço, no estar perto, com respeito a diversidade e, que desenvolva ações, sobretudo, solidárias. Libâneo (2010) acrescenta que as atividades educativas podem ocorrer sob várias 
modalidades e formas de organização, assumindo atributos que se aproximam de outras instituições e atividades fora de seu marco próprio, e assim contribui:

A educação consiste, pois, de uma prática social que envolve o desenvolvimento dos indivíduos no processo de sua rela ção a tiva com o meio naturale social, mediante a atividade cognoscitiva neces sária para tornar mais produtiva, efetiva, cria dora, a a tividade humana prática . (LIBÂNEO, 2010,p. 142)

A Acolhida Cidadã convida a todos ao exercício da empatia, do bom senso, da troca de experiências e saberes, da integração e do acolhimento afetuoso entre os calouros, veteranos e a comunidade acadêmica. São ações mais humanas e produtivas que contribuirão para que a universidade entregue para a sociedade profissionais e cidadãos mais empáticos e preocupados com a coletividade.

\section{CONTEXTO E DETALHAMENTO DAS ATIVIDADES}

A cada início de semestre letivo, as Unidades Educacionais e Administrativas, por meio das direções, coordenações, diretórios e centros acadêmicos, preparam programações a fim de estimular práticas de cidadania e responsabilidade social, em que os estudantes veteranos são os protagonistas das ações desenvolvidas.

A Pró-reitoria de Assuntos Estudantis - PRAE, por meio da Coordenação de Acompanhamento e Apoio Pedagógico ao Estudante - CAAPE é responsável atualmente pela Acolhida, centralizando todas as ações, a fim de viabilizar a estrutura necessária ao desenvolvimento dos projetos, como: coffe break, material impresso, material de divulgação, camisetas, viaturas para o deslocamento, material de consumo, entre outros. As ações da Acolhida são desenvolvidas, em sua maioria, nas primeiras duas semanas de cada semestre letivo. Os interessados em participar devem submeter seus projetos no Sistema de Inscrições da FURG - SINSC, que geralmente acontece com 90 dias de antecedência, em relação ao início do período letivo. No espaço de

Recebido em: 30 /04/ 2020 
inscrição é disponibilizado, pela CAAPE/PRAE, um edital com as orientações para participação e o modelo de projeto a ser submetido.

O número de projetos envolvidos no Programa vem crescendo a cada ano. Em 2013, por exemplo, foram 13 propostas, com 90 atividades desenvolvidas. No ano de 2020, já totalizamos 71 propostas e 507 atividades, o que demonstra que as práticas desse rito de entrada no ambiente universitário não precisam ser violen tas e abu sivas. Ao contrário, vislumbram-se ações fundamentadas em um processo de humanização, no qual “[...] cabe, também, à educação a responsabilidade de abrir as portas da mente e do coração e de apontar horizontes de construção partilhada de sociedades hu manas mais humanizadas" (BRANDÃO, 2002, p. 22).

As principais atividades interdisciplinares desenvolvidas nos projetos inscritos na Acolhida Cidadã são gincanas solidárias, trilhas ecológicas, passeios turísticos, palestras, atividades artísticas e culturais, cine debates, feiras multiculturais, cafés solidários, doações de sangue, roupas e alimentos, oficinas de artesanato, entre ou tras. No final de cada ano letivo, é organizado um Seminário de Encerramento da Acolhida Cidadã, que consiste num espaço de diálogos e troca de saberes, acerca dos projetos já realizados no início do primeiro e do segundo semestres letivos.

No ano de 2019, a Acolhida Cidadã ganhou destaque com uma página no site da Universidade $^{1}$, na qual a comunidade acadêmica pôde acompanhar a programação da Acolhida, nos diferentes cursos, institutos e campus da FURG. No site é possível, também, obter informações complementares sobre o histórico da Acolhida, editais e os Anais, já publicados com os trabalhos dos estudantes envolvidos. Assim, por meio da Acolhida Cidadã a Universidade busca oferecer um ambiente igualitário, no qual os estudantes possam desenvolver-se pessoal e academicamente, acolhendo da melhor

\footnotetext{
${ }^{1}$ https://acolhidacidada.furg.br/
} 
forma possível a diversidade que caracteriza a FURG, como instituição pública de Ensino Superior.

\section{ANÁLISE E DISCUSSÃO DO RELATO}

Desde a Idade Média, o trote universitário, originário na Europa (MATTOSO, 1985), tornou-se uma prática entre os estudantes como "ritual de passagem" e para além da dita "integração", gerava violências e constrangimentos. Logo, a Acolhida Cidadã vem desmistificando esse ciclo vicioso e mostrando que não é preciso domesticar nenhum “bixo”, muito menos, sermos cúmplices de uma cultura do silêncio.

Ao longo destes anos de Acolhida Cidadã na FURG, uma das lutas dessa Instituição foi fazer com que os estudantes entendessem que o trote não é saudável. Mesmo que eles digam "Eu que quis participar do trote!", isso fere o princípio da dignidade humana, ao qual não se pode omitir-se. A dignidade da pessoa humana é um dos princípios fundamentais no Brasil, prevista no Art. $1^{\circ}$, Inciso III da Constitu ição da República Federativa de 1988 e está vinculada aos direitos e deveres do cidadão. O principal objetivo desse artigo é a busca pela igualdade, pelo bem-estar de todos, pelo respeito ao próximo, direito à segurança, a liberdade de manifestação do pens a mento, entre outros.

O trote, como manifestação ou tentativa de ridicularizarão dos calouros não promove uma recepção acolhedora de iniciação na Universidade, mas sim uma reprodução histórica de uma ideia medieval do "Olho por olho, dente por dente". A FURG não tem apenas por responsabilidade a formação profissional dos estudantes que nela ingressam e sim, a incumbência de propagar valores que possam constituir-se em relações sociais e humanas mais solidárias. Só assim cumprirá a sua missão, que é formar profissionais capazes de contribuir para o desenvolvimento humano e a melhoria da qualidade socioambiental.

Recebido em: 30 /04/ 2020 
O Programa tem sido elogiado pelos estudantes e por suas famílias, que chegam até a Universidade, reforçando que devemos acolher todos que chegam, abraçando su as culturas e construindo conhecimentos, sem perder o respeito ao próximo e principalmente à vida. O impacto positivo do Programa é evidenciado nos Seminários de Acolhida, que ocorrem em cada final de ano letivo, nos quais os estudantes compartilham suas experiências com a comunidade universitária, expressando as vivências que a Acolhida Cidadã proporciona, além do sentimento de pertencimento ao ambiente universitário, que é promovido na construção e desenvolvimento dos projetos.

Para construir essa escrita, metodologicamente, optou-se por fazer uma busca na programação da Acolhida Cidadã dos últimos três anos - 2017, 2018 e 2019 - com objetivo de identificar o foco das ações propostas e desenvolvidas nessas acolhidas. O objetivo foi categorizá-las para compreender como vem se constituindo a Acolhida Cidadã, na FURG. Desse estudo resultou que ações realizadas nos últimos três anos podem ser agrupadas em seis categorias:

$1^{a}$ - Atividades acadêmicas de integração ao campus e cursos;

$2^{a}$ - Atividades com foco na sustentabilidade;

$3^{a}$ - Atividades solidárias;

$4^{a}$ - Atividades culturais e turísticas;

$5^{a}$ - Atividades lúdicas e esportivas;

$6^{a}$ - Práticas relacionadas à saúde.

Dentre elas, a categoria que apresentou um maior número de ações desenvolvidas nos últimos três anos do Programa foi a quarta Atividades culturais e turísticas, estando presente em todos os projetos, no total superior há $60 \%$ das atividades. Em relação a abrangência do projeto, percebeu-se que todas as unidades acadêmicas estão envolvidas na Acolhida e, ainda, algumas unidades administrativas, até mesmo dando su porte na estrutura. Os campi fora da sede - Santo Antônio da Patrulha, Santa Vitória do Palmar e 
São Lourenço do Sul participam ativamente da Acolhida Cidadã, nos últimos anos realizando projetos integrados nos campi.

\section{DADOS DA AVALIAÇÃO REALIZADA DA ACOLHIDA CIDADÃ}

A ideia de realizar uma avaliação do Programa surgiu durante uma das apresentações do mesmo na Mostra de Produção Universitária - MPU da FURG, em 2018, por uma das bolsistas da Acolhida, que foi desafiada pela banca, que a interrogou: “Porque não fizeram uma avaliação da Acolhida?” Pensando nesse questionamento e na responsabilidade que a PRAE possui para e com esse Programa, no ano de 2019, promoveu-se a avaliação da Acolhida.

Então, ao final da consulta, participaram 44 discentes, 18 docentes e 09 TAE, que responderam algumas questões ${ }^{2}$. Dentre os resultados, percebe-se que um número expressivo de estudantes respondeu que se sentiram bem recepcionados, in te grados e orientados na Acolhida Cidadã. Consideraram que o Programa transformou o ingresso deles na universidade, proporcionando uma experiência única e em alguns casos foi decisivo para a permanência na FURG. Somente uma pessoa ressaltou que o trote é legal e outra comentou que algumas atividades precisam ser qualificadas.

A maioria dos docentes avaliou que a Acolhida Cidadã incentiva boas práticas, de forma humanizada, ao desenvolver ações solidárias, carinhosas e respeitosas, que desencadeiam um ciclo de harmonia e gentileza, bem como fortalece o sentimento de pertencimento a comunidade acadêmica. Também avaliaram que o término do trote está intimamente relacionado com o aumento e a qualidade das ações desenvolvidas no Programa. Entretanto, dois docentes ressaltaram que acham um exagero os veteranos participarem de todas atividades da Acolhida, pois se torna um tempo perdido paraeles

\footnotetext{
${ }^{2}$ https://prae.furg.br/images/Relatrio_de_Avaliao_da_Acolhida_2010_2020.pdf
}

Recebido em: 30 /04/ 2020 
e avaliam que seria mais proveitoso diminuir o tempo das atividades, pois com as duas semanas a FURG perde seu foco, que é a formação e, ainda, atrasa o calendário de aulas.

A preocupação que os dois docentes manifestam em relação aos prazos, conteúdos e calendários são uma lógica difícil de ser superada, mesmo no desenvolvimento de programas institucionais. Para Diniz e Rodrigues (2020)

O desenvolvimento de um trabalho eficiente executado pelos professores do século XXI nãoé isento de tensões diversas, pois deixar para trás o paradigma dasociedade anteriormente denominada como industrial e passar para a complexa sociedade atual requer rápidas e profundas mudanças tanto em sua pratica profissional como no seu modo de perceber o a to educativo e sua relação com seus educandos, p ois tal papel inovador devem o levar a se tornar um professor reflexivo, dialógico e investiga dor (p. 231).

A maioria dos TAE também acredita que a Acolhida Cidadã incentiva boas práticas como solidariedade, af eto e respeito ao próximo, desenvolvendo a criatividade e auxiliando na integração e na permanência dos estudantes, de forma mais humanizada.

Segundo eles, o Programa desmistifica a questão do trote e instaura outra lógica de acolhimento e ritual de passagempara os ingressantes.

A maioria dos discentes também avaliaram que a Acolhida cidadã incentiv a boas práticas, de forma eficiente e cidadã, que geram integração, empatia e reciprocidade. Na avaliação dos estudantes, o Programa encoraja a participação e o diálogo dos acadêmicos desde o seu ingresso na Universidade, amenizando efeitos que às vezes são negativos nessa nova etapa e isso transforma a experiência de acolher na FURG, uma iniciativa diferenciada e criativa.

\section{CONSIDERAÇÕES FINAIS}

Há dez anos surgia um programa institucional que visava recepcionar com alegria e integrar de forma carinhosa e humanizada os novos estudantes à vida universitária, a

Recebido em: 30 /04/ 2020 
Acolhida Cidadã/Solidária. Apesar de ser uma proposta com objetivos muito bem definidos, não foi nada fácil implementar, pois havia muita resistência dos estudantes em mudar o paradigma do trote e também dos servidores (docentes e TAE), pois se tornaria mais um trabalho para ser executado.

Entretanto, essa reflexão sobre as dificuldades não nos colocou, enquanto PRAE, numa situação de impossibilidade diante da mudança, mas de esperança, pois como dizia Freire ao se referir à mudança "Mudar é difícil, mas possível” (FREIRE, 2000). Vivemos a 'boniteza de um sonho', como nos ensina Gadotti (2003) porque fomos aprendendo nesses últimos dez anos, que o protagonismo é fundamental e que uma iniciativa construída coletivamente é, sobretudo, um espaço de expressão das representatividades, da criatividade e da solidariedade.

As atividades da Acolhida Cidadã têm contribuído para melhorar a qualidade do ensino e da formação ampliada dos estudantes, pois, além de incentiv ar boas práticas de acolhimento, integram a comunidade universitária e valorizam as ações de solidariedade e responsabilidade social. Pensando na cidadania e no respeito que cada um merece, por ter conquistado seu espaço na universidade, é que a FURG, hoje, é referência de práticas saudáveis de acolhimento.Ademais, os vínculos estabelecidos pelos estudantes no processo de acolhimento têm um impacto positivo na adaptação dos ingress antes, o que vai influenciar futuramente no desempenho acadêmico e, muitas vezes, minimizar os processos de retenção e evasão, que muito tem nos mobilizado no seu enfrentamento, enquanto instituição.

\section{REFERÊNCIAS}

BRASIL. Presidência da República. Constituição da República Federativa do Brasil de 1988. Diário Oficial da União, Brasília, DF, Seção 1, p. 1, 05 out. 1988.

BRANDÃO, C. A educação popular na escola cidadã. Petrópolis: Vozes, 2002.

Recebido em: 30 /04/ 2020 
DINIZ, M. I. G; RODRIGUES, L. A. A pesquisa como princípio pedagógico: Os desafios na práxis docente para ressignificação de conhecimentos. In.: Revista Insignare Scientia- RIS (Edição Especial: A Pesquisa como Princípio Pedagógico) v. 3, n. 3, 2020.

FERREIRA, A. B. H. Novo Dicionário Aurélio. Rio de Janeiro: Nova Fronteira, 1975.

FREIRE, P. Pedagogia da esperança: Um reencontro com a Pedagogia do Oprimido. Rio de Janeiro: Paz e Terra, 1997.

Pedagogia da indignação: cartas pedagógicas e outros escritos. São Paulo: Editora UNESP, 2000.

Pedagogia da autonomia: saberes necessários à prática educativa. São Paulo: Paz e Terra, 2007.

FURG, Universidade Federal Do Rio Grande - Resolução 008/2004 que dispõe sobre o Ato Executivo n ${ }^{\circ}$ 011/2004, que proíbe o trote na FURG, da Secretaria Geral dos Conselhos Superiores da FURG, 2004.

Universidade Federal Do Rio Grande - Deliberaçãon ${ }^{0}$ 164/2010 que dispõe sobre a implementação do Programa de Acolhida Cidadã/Solidária, do Conselho de Ensino, Pesquisa, Extensão e Administração - COEPEA, 2010.

GADOTTI, M. Boniteza de um Sonho: ensinar e aprender com sentido (Novo. Hamburgo (RS): FEEVALE, 2003, 79 p.

LIBÂNEO, J. C. Pedagogia e pedagogos, para quê? 12. Ed. São Paulo. Cortez, 2010. MATTOSO, G. O calvário dos carecas: História do trote estudantil. São Paulo: EMW Editores; 1985.

VÁZQUEZ, A. S. Convite à estética. Rio de Janeiro: Civilização Brasileira, 1999.

Recebido em: 30 /04/ 2020 